\title{
Detection and depth analyses of deep levels generated by ion implantation in $\mathrm{n}$ - and $\mathrm{p}$-type $4 \mathrm{H}$ - $\mathrm{SiC}$
}

\section{AUTHOR(S):}

Kawahara, Koutarou; Alfieri, Giovanni; Kimoto, Tsunenobu

\section{CITATION:}

Kawahara, Koutarou ... [et al]. Detection and depth analyses of deep levels generated by ion implantation in n- and p-type 4H-SiC. JOURNAL OF APPLIED PHYSICS 2009, 106(1): 013719.

\section{ISSUE DATE:}

2009-07

URL:

http://hdl.handle.net/2433/109895

\section{RIGHT:}

Copyright 2009 American Institute of Physics. This article may be downloaded for personal use only. Any other use requires prior permission of the author and the American Institute of Physics. The following article appeared in JOURNAL OF APPLIED PHYSICS 106, 013719 (2009) and may be found at http://link.aip.org/link/JAPIAU/v106/i1/p013719/s1 


\title{
Detection and depth analyses of deep levels generated by ion implantation in $n$ - and $p$-type $4 H$-SiC
}

\author{
Koutarou Kawahara, ${ }^{\text {a) }}$ Giovanni Alfieri, and Tsunenobu Kimoto ${ }^{\text {b) }}$ \\ Department of Electronic Science and Engineering, Kyoto University, Katsura, Nishikyo, Kyoto 615-8510, \\ Japan
}

(Received 11 February 2009; accepted 7 June 2009; published online 14 July 2009)

\begin{abstract}
The authors investigated deep levels in the whole energy range of bandgap of $4 \mathrm{H}$-SiC, which are generated by low-dose $\mathrm{N}^{+}, \mathrm{P}^{+}$, and $\mathrm{Al}^{+}$implantation, by deep level transient spectroscopy (DLTS). $\mathrm{Ne}^{+}$-implanted samples have been also prepared to investigate the pure implantation damage. In the $n$-type as-grown material, the $\mathrm{Z}_{1 / 2}\left(E_{C}-0.63 \mathrm{eV}\right)$ and $\mathrm{EH}_{6 / 7}\left(E_{C}-1.6 \mathrm{eV}\right)$ centers are dominant deep levels. At least, seven peaks (IN1, IN3-IN6, IN8, and IN9) have emerged by implantation and annealing at $1000^{\circ} \mathrm{C}$ in the DLTS spectra from all $n$-type samples, irrespective of the implanted species. After high-temperature annealing at $1700{ }^{\circ} \mathrm{C}$, however, most DLTS peaks disappeared, and two peaks, IN3 and IN9, which may be assigned to $\mathrm{Z}_{1 / 2}$ and $\mathrm{EH}_{6 / 7}$, respectively, survive with a high concentration over the implanted atom concentration. In the $p$-type as-grown material, the $\mathrm{D}\left(E_{V}\right.$ $+0.40 \mathrm{eV})$ and HK4 $\left(E_{V}+1.4 \mathrm{eV}\right)$ centers are dominant. Two peaks (IP1 and IP3) have emerged by implantation and annealing at $1000{ }^{\circ} \mathrm{C}$, and four traps IP2 $\left(E_{V}+0.39 \mathrm{eV}\right)$, IP4 $\left(E_{V}+0.72 \mathrm{eV}\right)$, IP7 $\left(E_{V}+1.3 \mathrm{eV}\right)$, and IP8 $\left(E_{V}+1.4 \mathrm{eV}\right)$ are dominant after annealing at $1700{ }^{\circ} \mathrm{C}$ in all $p$-type samples. The IP2 and IP8 may be assigned to the HS1 and HK4 centers, respectively. The depth analyses have revealed that the major deep levels are generated in the much deeper region than the implant profile. (C) 2009 American Institute of Physics. [DOI: 10.1063/1.3159901]
\end{abstract}

\section{INTRODUCTION}

$\mathrm{SiC}$ is an attractive material for realizing high-power, high-temperature, and high-frequency devices. Deep levels in semiconductors have several harmful effects such as carrier trapping, an increase in leakage current, and a reduction in the minority carrier lifetime. For example, to realize $\mathrm{SiC}$ bipolar devices for high-voltage power switches, control of the carrier lifetime is an important issue which determines the on-state resistance as well as the switching speed. Therefore, deep levels should be reduced and then be controlled to fabricate high-performance $\mathrm{SiC}$ devices. Through fundamental studies on $\mathrm{SiC}$ growth and characterization in the past decade, deep levels in as-grown $4 H$ - $\mathrm{SiC}$, both $n$ - and $p$-type materials, have been mostly elucidated, ${ }^{1-6}$ although the microscopic structures of almost all the deep levels are still an open question.

For fabrication of any kinds of $\mathrm{SiC}$ devices, ion implantation is an essential process because of the low diffusion coefficients of dopants. ${ }^{7}$ In spite of the fact that various complicated point defects are generated by ion implantation, studies on deep levels in ion-implanted $\mathrm{SiC}$ have been very limited, leading to the lack of fundamental understanding of physical properties of implanted $\mathrm{SiC}$ and thereby $\mathrm{SiC}$ device performance. Although a few groups reported deep level transient spectroscopy (DLTS) measurements on $\mathrm{H}^{+} / \mathrm{He}^{+} / \mathrm{Ti}^{+} / \mathrm{V}^{+}$-implanted $n$-type $\mathrm{SiC},{ }^{1,8,9} \quad \mathrm{H}^{+}$-implanted $p$-type $\mathrm{SiC},{ }^{10} \mathrm{~N}^{+} / \mathrm{P}^{+}$-implanted $n$-type $\mathrm{SiC},{ }^{11-13}$ or $\mathrm{Al}^{+} / \mathrm{B}^{+}$-implanted $p$-type $\mathrm{SiC},{ }^{11,14}$ only deep levels energetically located in the upper half or lower half of bandgap,

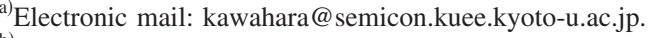

${ }^{b)}$ Also at Photonics and Electronics Science and Engineering Center (PESEC), Kyoto University.
}

respectively, were detected in those studies. Troffer et al. and Åberg et al. reported deep levels in $\mathrm{Al}^{+} / \mathrm{B}^{+}$-implanted $n$-type $\mathrm{SiC}{ }^{15,16}$ In the case of $n$-type doping, nitrogen and phosphorus are commonly employed as a dopant for deep-range implantation and for low sheet resistance, ${ }^{17}$ respectively. On the other hand, aluminum is commonly used as a dopant for $p$-type doping. ${ }^{14,18}$ In this paper, the authors present deep levels in the whole energy range of bandgap detected by DLTS, which are generated by low-dose $\mathrm{N}^{+}, \mathrm{P}^{+}$, and $\mathrm{Al}^{+}$ implantation into $4 H-\mathrm{SiC}$.

\section{EXPERIMENTS}

The starting materials were $\mathrm{N}$-doped $n$-type or Al-doped p-type $4 H$-SiC epilayers grown on $8^{\circ}$ off-axis $4 H$-SiC (0001). The thickness and doping concentration of epilayers were $10-15 \mu \mathrm{m}$ and $(7-8) \times 10^{15} \mathrm{~cm}^{-3}$, respectively. Multiple $\mathrm{N}^{+}, \mathrm{P}^{+}$, and $\mathrm{Al}^{+}$implantation was performed into separate samples at room temperature to form a $0.7-0.8-\mu \mathrm{m}$-deep box profile. The implantation energies and doses for each multiple implantation are summarized in Tables I-IV. Figure 1 shows the depth profile of implanted N atoms simulated by a TRIM code. ${ }^{19}$ The total implant dose was $5.6 \times 10^{10} \mathrm{~cm}^{-2}$. In this case, the concentration of implanted impurities (about $7 \times 10^{14} \mathrm{~cm}^{-3}$ ) is lower than the original doping level of epilayers. Although this implant dose is unusually low for device fabrication, the implanted region can simulate the "implant-tail" region. When the $p n$ junction is formed by ion implantation, deep levels located in the implant-tail region, where the depletion region is formed under the reverse bias, have significant effects on the leakage current. Since the samples keep the original conduction type ( $n$ - or $p$-type) under this implantation condition, deep levels 
TABLE I. $\mathrm{Al}^{+}$-implantation energies and doses for forming box profiles with a mean implanted atom concentration of about $7 \times 10^{14} \mathrm{~cm}^{-3}$ and a depth of about $0.8 \mu \mathrm{m}$.

\begin{tabular}{cc}
\hline \hline $\begin{array}{c}\text { Energy } \\
(\mathrm{keV})\end{array}$ & $\begin{array}{c}\text { Dose } \\
\left(\times 10^{9} \mathrm{~cm}^{-2}\right)\end{array}$ \\
\hline 700 & 18.7 \\
450 & 13.3 \\
300 & 8.46 \\
180 & 7.47 \\
100 & 3.83 \\
55 & 2.31 \\
24 & 1.42 \\
10 & 0.49 \\
\hline \hline
\end{tabular}

located in the upper half of the bandgap can be monitored by using $n$-type epilayers, irrespective of the implant species, and in the same way, deep levels in the lower half of the bandgap by using $p$-type materials. $\mathrm{Ne}^{+}$-implanted samples with the same implant dose were also prepared to investigate the pure implantation damage. Postimplantation annealing was carried out at $1000{ }^{\circ} \mathrm{C}$ for $2 \mathrm{~min}$ or $1700^{\circ} \mathrm{C}$ for $30 \mathrm{~min}$ in Ar ambient. In the high-temperature annealing at $1700{ }^{\circ} \mathrm{C}$, a carbon cap was employed to suppress the surface roughening. ${ }^{20}$

In DLTS measurements, $\mathrm{Ni}$ and $\mathrm{Ti}$ were employed as Schottky contacts with a thickness of approximately $80 \mathrm{~nm}$ on $n$ - and $p$-type samples, respectively. The typical diameter of Schottky contacts was $1 \mathrm{~mm}$. A $\mathrm{Ti} / \mathrm{Al} / \mathrm{Ni}$ $(20 \mathrm{~nm} / 140 \mathrm{~nm} / 50 \mathrm{~nm})$ layer annealed at $1000{ }^{\circ} \mathrm{C}$ for 2 min was employed as back side Ohmic contacts for $p$-type materials in order to obtain reliable capacitance values in $C-V$ and DLTS measurements. The reverse bias was adjusted so that deep levels in the box-profile region can be monitored. The filling pulse was applied for 10 or $100 \mathrm{~ms}$ to $n$-and $p$-type materials, respectively, and the period width for transient measurements was $200 \mathrm{~ms}$. The depth profiles of deep level concentrations were also measured by changing the bias voltage in DLTS measurements. To measure the trap concentration far below from the surface, samples are etched down to a depth of about $0.7 \mu \mathrm{m}$ by reactive ion etching (RIE).

TABLE II. $\mathrm{N}^{+}$-implantation energies and doses for forming box profiles with a mean implanted atom concentration of about $7 \times 10^{14} \mathrm{~cm}^{-3}$ and a depth of about $0.8 \mu \mathrm{m}$.

\begin{tabular}{cc}
\hline \hline $\begin{array}{c}\text { Energy } \\
(\mathrm{keV})\end{array}$ & $\begin{array}{c}\text { Dose } \\
\left(\times 10^{9} \mathrm{~cm}^{-2}\right)\end{array}$ \\
\hline 700 & 11.7 \\
500 & 9.74 \\
330 & 9.74 \\
220 & 7.79 \\
140 & 6.42 \\
80 & 5.35 \\
40 & 3.30 \\
18 & 1.94 \\
\hline \hline
\end{tabular}

TABLE III. $\mathrm{P}^{+}$-implantation energies and doses for forming box profiles with a mean implanted atom concentration of about $7 \times 10^{14} \mathrm{~cm}^{-3}$ and a depth of about $0.8 \mu \mathrm{m}$.

\begin{tabular}{cc}
\hline \hline $\begin{array}{c}\text { Energy } \\
(\mathrm{keV})\end{array}$ & $\begin{array}{c}\text { Dose } \\
\left(\times 10^{9} \mathrm{~cm}^{-2}\right)\end{array}$ \\
\hline 700 & 19.9 \\
450 & 12.9 \\
300 & 8.61 \\
180 & 6.99 \\
100 & 3.77 \\
50 & 2.15 \\
24 & 1.08 \\
10 & 0.59 \\
\hline \hline
\end{tabular}

\section{RESULTS AND DISCUSSION}

\section{A. Deep levels detected in $n$-type materials}

In the DLTS spectra of nonimplanted $n$-type $4 H$-SiC (both as-grown and annealed at $\left.1700{ }^{\circ} \mathrm{C}\right)$, the $\mathrm{Z}_{1 / 2}\left(E_{C}\right.$ $-0.63 \mathrm{eV})^{1}$ and $\mathrm{EH}_{6 / 7}\left(E_{C}-1.6 \mathrm{eV}\right)^{2}$ centers were dominant. The trap concentration was about $2 \times 10^{13} \mathrm{~cm}^{-3}$.

In DLTS measurements on implanted samples, the region (depth) monitored by DLTS should be taken into account because generation of a high density traps may result in the formation of highly resistive compensated region. Figure 2 shows the depth profile of the net donor concentration calculated from $C-V$ measurements on $\mathrm{Al}^{+}$- or $\mathrm{N}^{+}$-implanted samples. In the $\mathrm{Al}^{+} / \mathrm{N}^{+}$-implanted samples annealed at $1000{ }^{\circ} \mathrm{C}(\mathrm{Al}-1000 / \mathrm{N}-1000)$, a high-resistance region is formed near the surface ranged to the depth of about $0.75 \mu \mathrm{m} / 0.50 \mu \mathrm{m}$, which is derived from the fitting of $C-V$ curve. Therefore, the region monitored by DLTS measurements on ion-implanted samples annealed at $1000{ }^{\circ} \mathrm{C}$ must be deeper than the high-resistance region (a depth of $0.75 \mu \mathrm{m} / 0.50 \mu \mathrm{m}$ for $\mathrm{Al}^{+} / \mathrm{N}^{+}$-implanted samples). On the other hand, the main box-profile region can be monitored by DLTS on the samples annealed at $1700{ }^{\circ} \mathrm{C}$ due to the absence of the compensated region.

Figure 3 represents the DLTS spectra obtained from $\mathrm{Al}^{+}$-implanted, $\mathrm{N}^{+}$-implanted, or $\mathrm{Ne}^{+}$-implanted samples annealed at 1000 or $1700{ }^{\circ} \mathrm{C}$. Here, signal $b_{1}$ is the coefficient of the first sine term in the Fourier series of deep level transient Fourier spectroscopy. ${ }^{21}$ In the DLTS spectra from the

TABLE IV. $\mathrm{Ne}^{+}$-implantation energies and doses for forming box profiles with a mean implanted atom concentration of about $7 \times 10^{14} \mathrm{~cm}^{-3}$ and a depth of about $0.8 \mu \mathrm{m}$

\begin{tabular}{cc}
\hline \hline $\begin{array}{c}\text { Energy } \\
(\mathrm{keV})\end{array}$ & $\begin{array}{c}\text { Dose } \\
\left(\times 10^{9} \mathrm{~cm}^{-2}\right)\end{array}$ \\
\hline 700 & 15.6 \\
450 & 12.5 \\
280 & 10.2 \\
180 & 7.30 \\
100 & 5.43 \\
50 & 2.84 \\
24 & 1.42 \\
10 & 0.69 \\
\hline
\end{tabular}




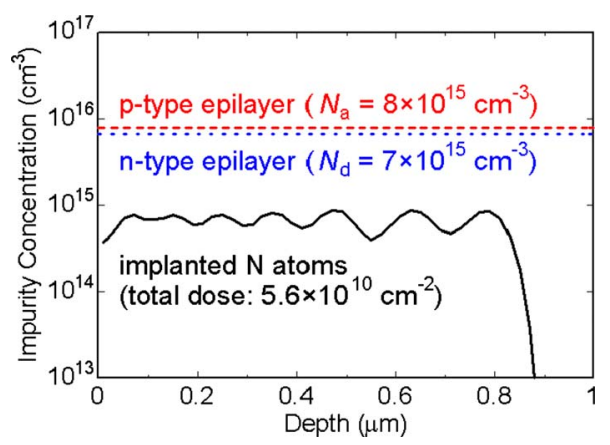

FIG. 1. (Color online) Depth profiles of implanted $\mathrm{N}$ atoms simulated by TRIM code (solid line: implanted $\mathrm{N}$ concentration, dots/broken lines: doping levels in $n$-/ $p$-type starting materials).

$\mathrm{Al}^{+}$-implanted sample, at least, seven peaks labeled IN1, IN3-IN6, IN8, and IN9 emerged by implantation and annealing at $1000{ }^{\circ} \mathrm{C}$. After high-temperature annealing at $1700{ }^{\circ} \mathrm{C}$, however, most DLTS peaks disappeared, and two peaks, IN3 and IN9, survived. From the Arrhenius plots of emission time constants assuming a temperature-independent capture cross section, the energy levels and the capture cross sections of the observed traps were determined, which are summarized in Table V. In addition, the trap concentration in $\mathrm{Al}^{+}$-implanted samples annealed at $1000{ }^{\circ} \mathrm{C} / 1700{ }^{\circ} \mathrm{C}$ is also shown in the same table. The trap concentration obtained for the sample annealed at $1000{ }^{\circ} \mathrm{C}$ may suffer from a large error because the trap concentration is close to the doping level. The trap concentration in the sample annealed at $1000{ }^{\circ} \mathrm{C}$ may be even higher in the surface region, leading to the formation of the compensated region, as discussed on $\mathrm{p}$. 4. The heights of the IN3 and IN9 peaks in the $\mathrm{N}^{+}$-implanted sample are much higher than those in the $\mathrm{Al}^{+} / \mathrm{Ne}^{+}$-implanted samples. This may originate from the difference in the detected region. As discussed on p. 4, the high-resistance region in the $\mathrm{N}^{+}$-implanted sample is thinner than that in the $\mathrm{Al}^{+} / \mathrm{Ne}^{+}$-implanted samples. Therefore, the region monitored by DLTS on the $\mathrm{N}^{+}$-implanted sample will contain the boxprofile region where many collisions occurred during ion implantation. The dominant levels after $1700{ }^{\circ} \mathrm{C}$ annealing,

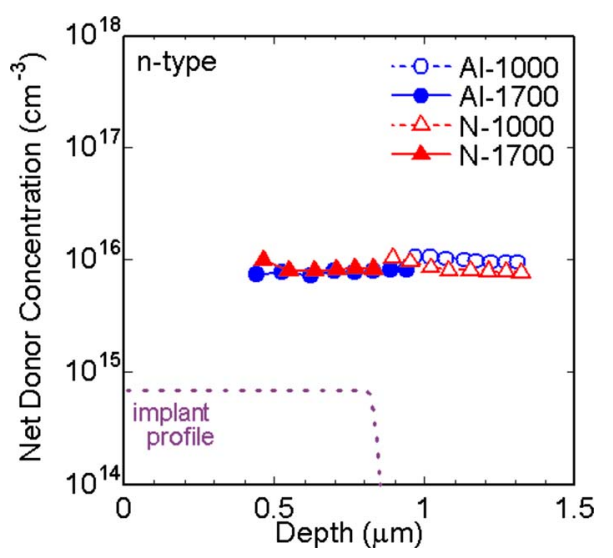

FIG. 2. (Color online) Depth profile of net donor concentration (Al-1000: $\mathrm{Al}^{+}$-implanted sample annealed at $1000{ }^{\circ} \mathrm{C}, \mathrm{Al}-1700: \mathrm{Al}^{+}$-implanted sample annealed at $1700{ }^{\circ} \mathrm{C}, \mathrm{N}-1000: \mathrm{N}^{+}$-implanted sample annealed at $1000{ }^{\circ} \mathrm{C}$, and $\mathrm{N}-1700$ : $\mathrm{N}^{+}$-implanted sample annealed at $1700^{\circ} \mathrm{C}$ ). The highresistance region does not exist in the sample annealed at $1700^{\circ} \mathrm{C}$.

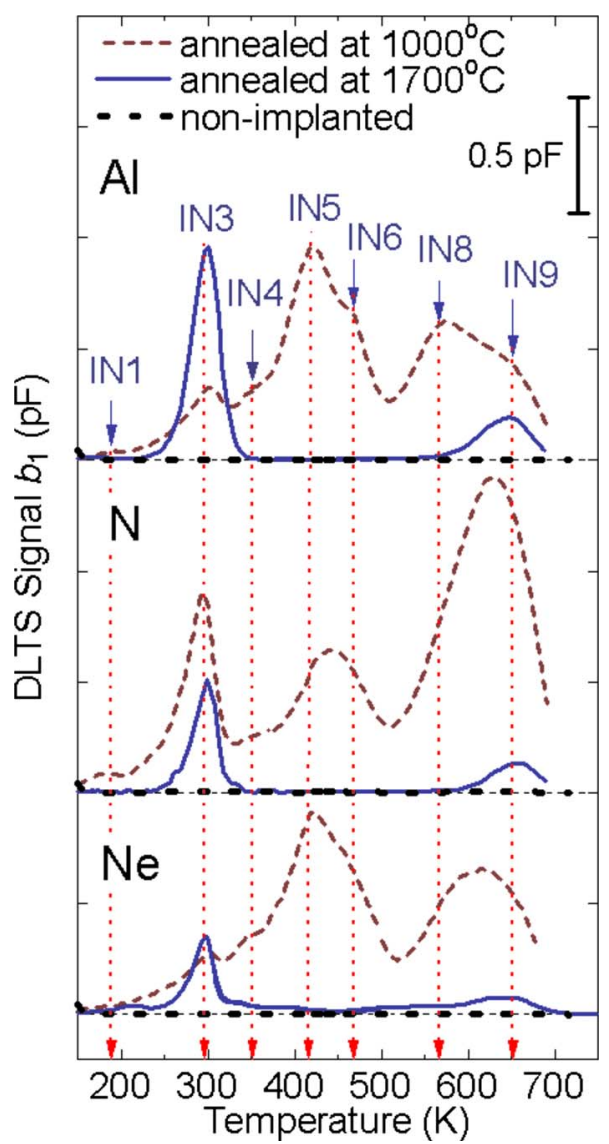

FIG. 3. (Color online) DLTS spectra of the $n$-type $4 H$-SiC implanted with $\mathrm{Al}^{+}, \mathrm{N}^{+}$, and $\mathrm{Ne}^{+}$(implant dose: $5.6 \times 10^{10} \mathrm{~cm}^{-2}$ ) annealed at $1000{ }^{\circ} \mathrm{C}$ (broken line) and $1700{ }^{\circ} \mathrm{C}$ (solid line). The spectrum of the nonimplanted sample is indicated with a dotted line. Signal $b_{1}$ is the coefficient of the first sine term in the Fourier series, which is proportional to the trap concentration.

IN3 and IN9 traps, may be assigned to the well known $Z_{1 / 2}$ and $\mathrm{EH}_{6 / 7}$ centers, respectively, based on their energy levels and thermal stability.

In the $\mathrm{N}^{+}$-implanted sample, although the DLTS spectrum after implantation and annealing at $1000{ }^{\circ} \mathrm{C}$ looks different from that for the $\mathrm{Al}^{+}$-implanted sample, the authors speculate that there are also seven (or eight) traps because two peaks around 440 and $630 \mathrm{~K}$ are too broad to be assigned to a single level. Figure 4 shows the fitting results for DLTS spectra presented in Fig. 3. In the fitting, eight traps

TABLE V. Energy positions and capture cross sections of deep levels observed in the ion-implanted $n$-type $4 H-\mathrm{SiC}$ ( $\sigma$ : the capture cross section, $N_{T}$ : the concentration of traps in the $\mathrm{Al}^{+}$-implanted $\mathrm{SiC}$ annealed at 1000 or $\left.1700{ }^{\circ} \mathrm{C}\right)$.

\begin{tabular}{lcccc}
\hline \hline Label & $\begin{array}{c}E_{C}-E_{T} \\
(\mathrm{eV})\end{array}$ & $\begin{array}{c}\sigma \\
\left(\mathrm{cm}^{-2}\right)\end{array}$ & $\begin{array}{c}N_{T} \\
\left(\mathrm{~cm}^{-3}\right)\left(1000{ }^{\circ} \mathrm{C}\right)\end{array}$ & $\begin{array}{c}N_{T} \\
\left(\mathrm{~cm}^{-3}\right)\left(1700{ }^{\circ} \mathrm{C}\right)\end{array}$ \\
\hline IN1 & 0.28 & $10^{-17}$ & $1.9 \times 10^{14}$ & Not observed \\
IN3 & 0.63 & $10^{-14}$ & $1.9 \times 10^{15}$ & $2.8 \times 10^{15}$ \\
IN4 & 0.65 & $10^{-16}$ & $1.7 \times 10^{15}$ & Not observed \\
IN5 & 0.73 & $10^{-16}$ & $5.3 \times 10^{15}$ & Not observed \\
IN6 & 0.98 & $10^{-15}$ & $4.2 \times 10^{15}$ & Not observed \\
IN8 & 1.1 & $10^{-15}$ & $2.7 \times 10^{15}$ & Not observed \\
IN9 & 1.6 & $10^{-14}$ & $2.8 \times 10^{15}$ & $8.3 \times 10^{14}$ \\
\hline \hline
\end{tabular}




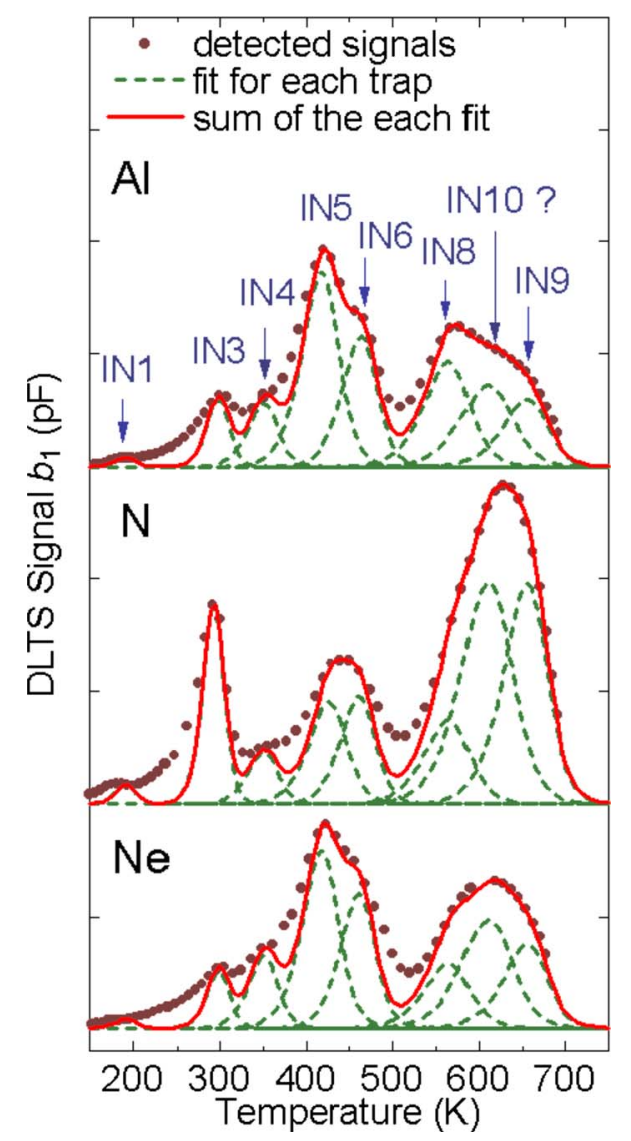

FIG. 4. (Color online) Fitting for each DLTS spectrum detected in the $n$-type $4 H$-SiC implanted with $\mathrm{Al}^{+}, \mathrm{N}^{+}$, and $\mathrm{Ne}^{+}$annealed at $1000{ }^{\circ} \mathrm{C}$ (closed circles: detected signals, dotted line: fit for each trap, and solid line: sum of the each fit).

(IN1, IN3-IN6, and IN8-IN10) with the fixed energy levels and capture cross sections were assumed, and the trap concentrations were varied, which means that the temperature position of each peak was fixed and the height of each peak was changed to fit each DLTS spectrum. As shown in Fig. 4, the broad DLTS peaks at 440 and $630 \mathrm{~K}$ seem to consist of major peaks: IN5 and IN6 and IN8-IN10, respectively. In the fitting process, an additional DLTS peak (IN10) was introduced in between IN8 and IN9 to reproduce the observed DLTS spectra. However, the accurate energy level and capture cross section of this trap are not clear due to the severe overlapping of the peaks. In addition, other additional peaks may exist because the fitted spectra deviate in the "valleys" of DLTS spectra, which are also difficult to be separated due to the severe overlapping. After annealing at $1700{ }^{\circ} \mathrm{C}$, again the $\mathrm{Z}_{1 / 2}$ and $\mathrm{EH}_{6 / 7}$ peaks dominate, as in the case of $\mathrm{Al}^{+}$ -implantation. Similar results were also obtained for $\mathrm{P}^{+}$-implanted (not shown) and $\mathrm{Ne}^{+}$-implanted samples.

Thus, the $\mathrm{Z}_{1 / 2}$ and $\mathrm{EH}_{6 / 7}$ centers, which are regarded as intrinsic defects related to the carbon displacement, ${ }^{3,422}$ are the dominant and stable deep levels in not only as-grown and electron-irradiated $4 \mathrm{H}$-SiC but also any implanted $4 \mathrm{H}$-SiC as far as the implant dose is low. In addition, all the traps, IN1, IN3-IN6, IN8, IN9 (and IN10) may be also intrinsic defects because these traps were generated in the $\mathrm{Al}^{+}, \mathrm{N}^{+}, \mathrm{P}^{+}$, and even $\mathrm{Ne}^{+}$-implanted samples. The IN5 and IN6 centers may be assigned to the $\mathrm{RD}_{1}$ and $\mathrm{RD}_{2}$ centers, ${ }^{1,2}$ respectively, from

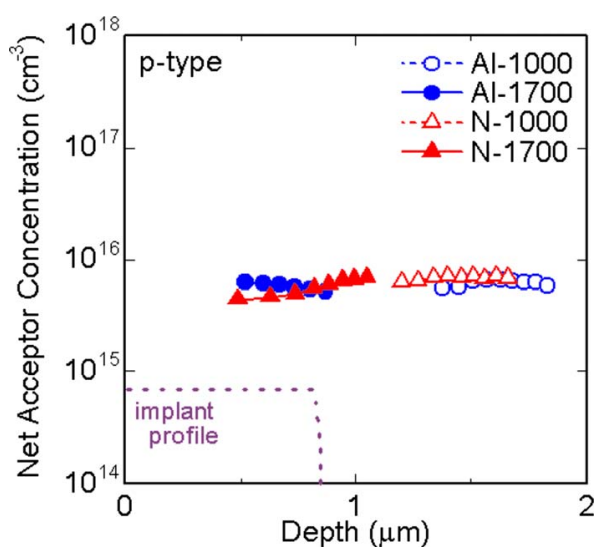

FIG. 5. (Color online) Depth profile of the net acceptor concentration (Al1000: $\mathrm{Al}^{+}$-implanted sample annealed at $1000{ }^{\circ} \mathrm{C}, \mathrm{Al}-1700$ : $\mathrm{Al}^{+}$-implanted sample annealed at $1700{ }^{\circ} \mathrm{C}, \mathrm{N}-1000: \mathrm{N}^{+}$-implanted sample annealed at $1000^{\circ} \mathrm{C}$, and $\mathrm{N}-1700$ : $\mathrm{N}^{+}$-implanted sample annealed at $1700^{\circ} \mathrm{C}$ ). The high-resistance region does not exist in the sample annealed at $1700{ }^{\circ} \mathrm{C}$.

their energy levels and capture cross sections. These centers were detected in $\mathrm{V}^{+}-\mathrm{Ti}^{+}-, \mathrm{Al}^{+}$-, and $\mathrm{B}^{+}$-implanted $4 \mathrm{H}-\mathrm{SiC}$ by Dalibor et al. ${ }^{1}$ and Hemmingsson et al., ${ }^{2}$ which are considered to be also intrinsic defects. Deep levels, which contain particular implanted impurities, may be generated when the implant dose is much higher.

The trap concentrations in the implanted samples were very high: the $\mathrm{Z}_{1 / 2}$ and $\mathrm{EH}_{6 / 7}$ concentrations were $2 \times 10^{15}$ and $8 \times 10^{14} \mathrm{~cm}^{-3}$, respectively, in the $\mathrm{Al}^{+}$-implanted sample after annealing at $1700{ }^{\circ} \mathrm{C}$, which is about two orders of magnitude higher than those in the nonimplanted sample.

\section{B. Deep levels detected in p-type materials}

In the DLTS spectra of a nonimplanted $p$-type $4 \mathrm{H}$-SiC (both as-grown and annealed at $\left.1700{ }^{\circ} \mathrm{C}\right)$, the $\mathrm{D}\left(E_{V}\right.$ $+0.40 \mathrm{eV})^{5,15}$ and HK4 $\left(E_{V}+1.4 \mathrm{eV}\right)^{6}$ centers were dominant. The trap concentration was in the $10^{12} \mathrm{~cm}^{-3}$ range.

Figure 5 shows the depth profile of the net acceptor concentration for $\mathrm{Al}^{+}$- or $\mathrm{N}^{+}$-implanted samples calculated from $C$ - $V$ measurements. In the $\mathrm{Al}^{+} / \mathrm{N}^{+}$-implanted $p$-type samples annealed at $1000{ }^{\circ} \mathrm{C}$, a high-resistance region also exists near the surface to a depth of about $1.3 \mu \mathrm{m} / 1.0 \mu \mathrm{m}$ and disappeared after $1700{ }^{\circ} \mathrm{C}$ annealing. Figure 6 represents the DLTS spectra obtained from $\mathrm{Al}^{+}$-implanted, $\mathrm{N}^{+}$-implanted, or $\mathrm{Ne}^{+}$-implanted samples annealed at 1000 or $1700{ }^{\circ} \mathrm{C}$. Table VI summarizes the energy levels and capture cross section of deep levels observed in the implanted $p$-type $4 H$-SiC. In the DLTS spectra from these samples, two peaks, labeled IP1 $\left(E_{V}+0.35 \mathrm{eV}\right)$ and IP3 $\left(E_{V}+0.70 \mathrm{eV}\right)$, emerged by implantation and annealing at $1000{ }^{\circ} \mathrm{C}$. After hightemperature annealing at $1700{ }^{\circ} \mathrm{C}$, four traps, labeled IP2 $\left(E_{V}+0.39 \mathrm{eV}\right)$, IP4 $\left(E_{V}+0.72 \mathrm{eV}\right)$, IP7 $\left(E_{V}+1.3 \mathrm{eV}\right)$, and IP8 $\left(E_{V}+1.4 \mathrm{eV}\right)$, are generated and are stable in the $p$-type materials except for IP4 in the $\mathrm{N}^{+}$-implanted sample. The generation of the IP4 center may strongly depend on the mass of the implant species ( $\mathrm{N}$ atom: the lightest in this study). On the other hand, IP1 and IP3 were almost annealed out by the thermal treatment at $1700{ }^{\circ} \mathrm{C}$. All the traps observed in the $p$-type $4 H$-SiC (IP1-IP4 and IP6-IP8) may be 


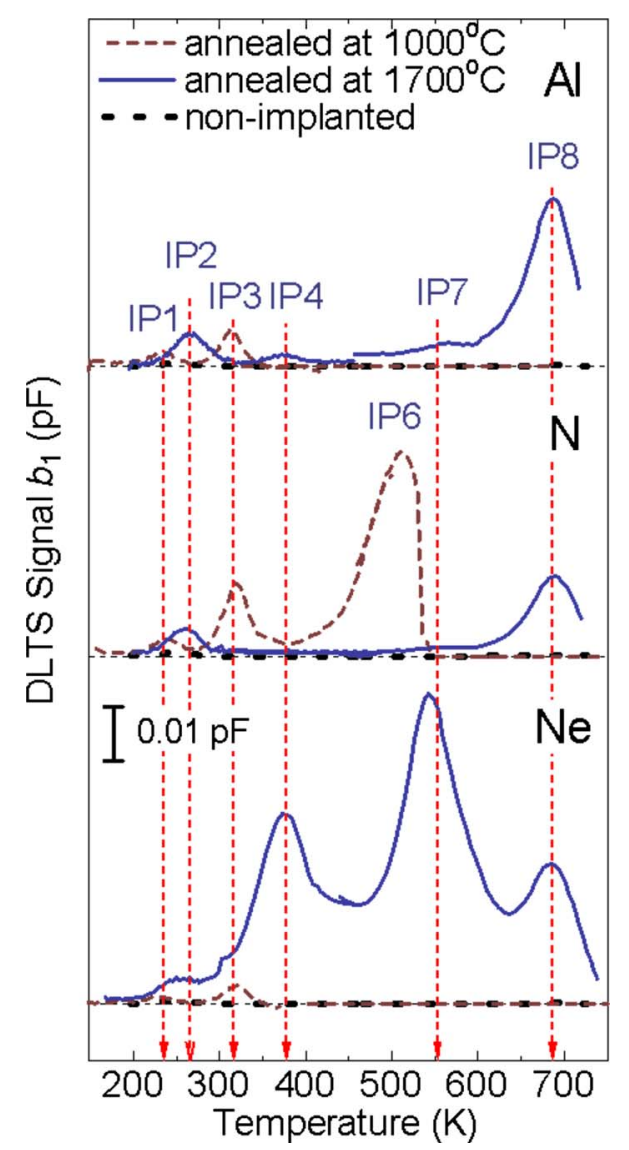

FIG. 6. (Color online) DLTS spectra of the $p$-type $4 H$-SiC implanted with $\mathrm{Al}^{+}, \mathrm{N}^{+}$, and $\mathrm{Ne}^{+}$(implant dose: $5.6 \times 10^{10} \mathrm{~cm}^{-2}$ ) annealed at $1000^{\circ} \mathrm{C}$ (broken line) and $1700{ }^{\circ} \mathrm{C}$ (solid line). The spectrum of the nonimplanted sample is indicated with a dotted line.

also attributed to intrinsic defects because these traps were detected even in the $\mathrm{Ne}^{+}$-implanted sample. Although the IP6 center looks nitrogen-specific trap, the authors speculate that the trap may be also an intrinsic defect and may exist with a low concentration in $\mathrm{Ne}^{+}$-implanted sample because the IP6 was observed in high-dose $\mathrm{Al}^{+}$-implanted sample (not shown). The reason why the IP6 center was observed with such a high concentration in the $\mathrm{N}^{+}$-implanted sample annealed at $1000{ }^{\circ} \mathrm{C}$ may be the same as that in $n$-type samples: the thickness of the high-resistance region is different, leading to the different regions monitored by DLTS. The dominant levels after annealing at $1700{ }^{\circ} \mathrm{C}$, IP2 and IP8,

TABLE VI. Energy positions and capture cross sections of deep levels observed in the ion-implanted $p$-type $4 H-\mathrm{SiC}$ ( $\sigma$ : the capture cross section, $N_{T}$ : the concentration of traps in the $\mathrm{Al}^{+}$-implanted $\mathrm{SiC}$ annealed at 1000 or $\left.1700{ }^{\circ} \mathrm{C}\right)$.

\begin{tabular}{|c|c|c|c|c|}
\hline Label & $\begin{array}{c}E_{T}-E_{V} \\
(\mathrm{eV})\end{array}$ & $\begin{array}{c}\sigma \\
\left(\mathrm{cm}^{-2}\right)\end{array}$ & $\begin{array}{cl} & N_{T} \\
\left(\mathrm{~cm}^{-3}\right) & \left(1000{ }^{\circ} \mathrm{C}\right)\end{array}$ & $\begin{array}{cl} & N_{T} \\
\left(\mathrm{~cm}^{-3}\right) & \left(1700{ }^{\circ} \mathrm{C}\right)\end{array}$ \\
\hline IP1 & 0.35 & $10^{-18}$ & $8.2 \times 10^{12}$ & Not observed \\
\hline IP2 & 0.39 & $10^{-18}$ & Not observed & $1.4 \times 10^{13}$ \\
\hline IP3 & 0.70 & $10^{-15}$ & $2.6 \times 10^{13}$ & Not observed \\
\hline IP4 & 0.72 & $10^{-16}$ & Not observed & $6.4 \times 10^{12}$ \\
\hline IP6 & 1.2 & $10^{-14}$ & Not observed & Not observed \\
\hline IN7 & 1.3 & $10^{-14}$ & Not observed & $1.0 \times 10^{13}$ \\
\hline IP8 & 1.4 & $10^{-16}$ & Not observed & $1.9 \times 10^{14}$ \\
\hline
\end{tabular}

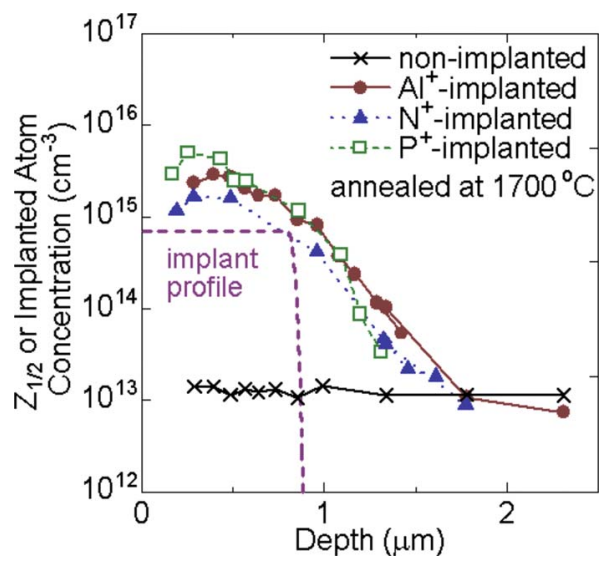

FIG. 7. (Color online) Depth profiles of $\mathrm{Z}_{1 / 2}$ concentration for the nonimplanted (cross marks) and $\mathrm{Al}^{+}$(closed circles)-, $\mathrm{N}^{+}$(closed triangles)-, and $\mathrm{P}^{+}$(open squares)-implanted $n$-type $4 H$-SiC after annealing at $1700{ }^{\circ} \mathrm{C}$ for $30 \mathrm{~min}$. The broken line shows the implant profile.

may be assigned to the $\mathrm{HS}^{3,23}$ and $\mathrm{HK} 4,{ }^{6}$ respectively, from the energy level and generation behaviors. The HS1 center is a thermally stable defect detected in electron-/protonirradiated $4 \mathrm{H}-\mathrm{SiC}$ reported by Storasta et al. They suggested that the HS1 center is correlated to the $\mathrm{D}_{\mathrm{I}}$ defect, which show the peculiar peaks in photoluminescence. ${ }^{24}$ Other levels, IP1 and IP4, may correspond to $\mathrm{UK} 1{ }^{6}$ and $\mathrm{HK} 0,{ }^{6}$ respectively, from the same reasons. The UK1 and HK0 centers were detected in the $p$-type $4 H$-SiC irradiated at energy over $160 \mathrm{keV}$ and in samples treated with RIE, respectively.

It should be also noted that the concentration of generated traps is $10^{13}-10^{14} \mathrm{~cm}^{-3}$ for the IP2, IP4, IP7, and IP8 centers, which is about one order of magnitude higher than that of the nonimplanted sample but is remarkably lower than that for defect centers observed in the implanted $n$-type materials.

\section{Depth profile of major deep levels}

Figure 7 shows the depth profiles of $Z_{1 / 2}$ (IN3) concentration for $\mathrm{Al}^{+}$-, $\mathrm{N}^{+}$-, and $\mathrm{P}^{+}$-implanted $n$-type $4 H$-SiC after $1700{ }^{\circ} \mathrm{C}$ annealing for $30 \mathrm{~min}$. The $\mathrm{Z}_{1 / 2}$ concentration to a depth of $1.4 \mu \mathrm{m}$ from the surface was measured by changing the bias voltage in DLTS measurements, and the concentration in the depth from about 1.0 to $2.3 \mu \mathrm{m}$ was measured by the same way after removing $0.7 \mu \mathrm{m}$ using RIE. The trap concentration in a nonimplanted sample is also plotted by the cross symbols. Although the implantation depth is about $0.8 \mu \mathrm{m}$, as indicated by a broken line in Fig. 7 , the $Z_{1 / 2}$ center was generated in a much deeper region than the implanted box profile. The real implant profile may be deeper than the TRIM simulation profile due to channeling effects, ${ }^{25,26}$ although secondary ion mass spectroscopy (SIMS) analyses of implanted species are difficult due to the very low concentration $\left(<7 \times 10^{14} \mathrm{~cm}^{-3}\right)$. The $\mathrm{Z}_{1 / 2}$ concentration near the surface for ion-implanted samples is about 100 times higher than that for the nonimplanted sample. It should be also noted that the trap concentration is several times higher than the implanted atom concentration (about $7 \times 10^{14} \mathrm{~cm}^{-3}$ ). This result also indicates that the $Z_{1 / 2}$ (and $\left.\mathrm{EH}_{6 / 7}\right)$ center does not contain any impurities. A TRIM simu- 


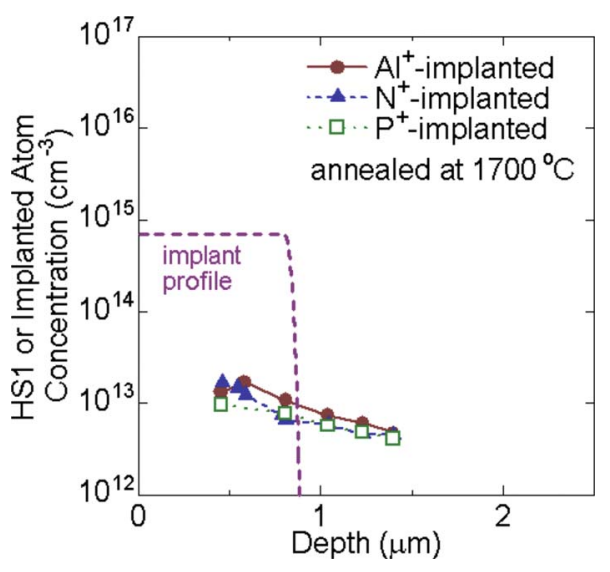

FIG. 8. (Color online) Depth profiles of HS1 concentration for $\mathrm{Al}^{+}$(closed circles)-, $\mathrm{N}^{+}$(closed triangles)-, and $\mathrm{P}^{+}$(open squares)-implanted $p$-type $4 H$-SiC after annealing at $1700{ }^{\circ} \mathrm{C}$ for $30 \mathrm{~min}$. The concentration of HS1 center in the nonimplanted sample is below $4 \times 10^{12} \mathrm{~cm}^{-3}$.

lation suggested that the concentrations of silicon and carbon vacancies generated by implantation exceed a mid- $10^{17} \mathrm{~cm}^{-3}$ in the implanted region. Although the implanted-ion dependence of the $Z_{1 / 2}$ concentration was rather small in this study, the $\mathrm{N}^{+}$-implanted sample exhibited a slightly lower $\mathrm{Z}_{1 / 2}$ concentration compared to $\mathrm{P}^{+}$- and $\mathrm{Al}^{+}$-implanted samples. This may originate from the smaller mass of $\mathrm{N}$ atoms and thereby smaller implantation damage. The $\mathrm{Z}_{1 / 2}$ concentration gradually decreases with the depth, and it reaches a value of the nonimplanted sample at a depth of 1.7-1.8 $\mu \mathrm{m}$.

Figure 8 shows the depth profile of HS1 (IP2) concentration which was obtained in the $\mathrm{Al}^{+}, \mathrm{N}^{+}$, and $\mathrm{P}^{+}$-implanted $p$-type $4 H$-SiC after annealing at $1700{ }^{\circ} \mathrm{C}$. Note that the HS1 concentration in a nonimplanted sample was below a mid- $10^{12} \mathrm{~cm}^{-3}$. The HS1 concentration is much lower than the implanted atom concentration as well as the $\mathrm{Z}_{1 / 2}$ concentration observed in the $n$-type materials (Fig. 7). The HS1 concentration also showed very small dependence on the implanted ion species. The depth profile of the HS1 concentration is relatively flat and shows a gentle decrease toward the bulk region. In the next step, deep levels in highdose implanted samples should be investigated.

\section{SUMMARY}

In summary, an overview of deep levels detected in this study is shown in Fig. 9, where the dominant and stable deep levels in the whole energy range of bandgap for the $4 \mathrm{H}-\mathrm{SiC}$ implanted with common dopant impurities are identified. When the implant dose is low $\left(5.6 \times 10^{10} \mathrm{~cm}^{-2}\right)$, the dominant deep levels are the $\mathrm{Z}_{1 / 2}\left(\mathrm{IN} 3: E_{C}-0.63 \mathrm{eV}\right)$ and $\mathrm{EH}_{6 / 7}$ (IN9: $E_{C}-1.6 \mathrm{eV}$ ) in the upper half of the bandgap, and HS1 (IP2: $E_{V}+0.39 \mathrm{eV}$ ) and HK4 (IP8: $\left.E_{V}+1.4 \mathrm{eV}\right)$ in the lower half of bandgap irrespective of the implant species. The $Z_{1 / 2}$ and HS1 centers were generated not only in the implanted region but also in a much deeper region than the implant profile. In particular, the concentrations of the $\mathrm{Z}_{1 / 2}$ and $\mathrm{EH}_{6 / 7}$ centers show significant increase (about 100 times higher than that measured in nonimplanted sample) near the surface by ion implantation even after annealing at $1700{ }^{\circ} \mathrm{C}$.

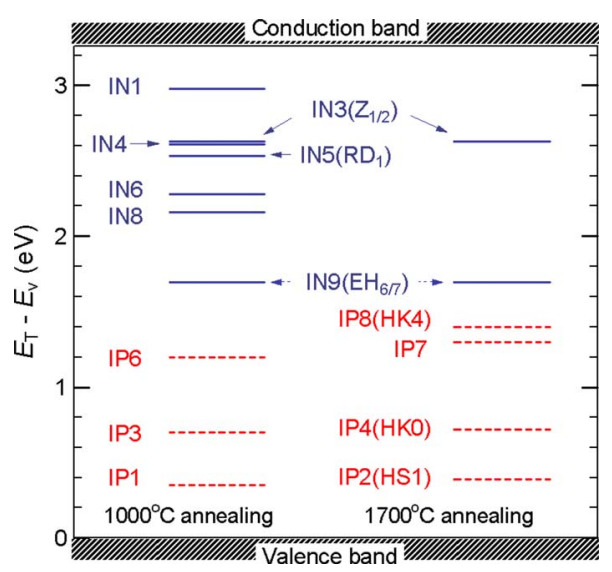

FIG. 9. (Color online) Overview of deep levels detected in $n$ (solid lines)- / $p$ (broken lines)-type $\mathrm{Al}^{+} / \mathrm{N}^{+} / \mathrm{P}^{+} / \mathrm{Ne}^{+}$-implanted $4 H$-SiC with a dose of $5.6 \times 10^{10} \mathrm{~cm}^{-2}$.

\section{ACKNOWLEDGMENTS}

This work was supported in part by a Grant-in-Aid for Scientific Research (Grant No. 21226008) from the Japan Society for the Promotion of Science and by Global COE Program (C09) from the Ministry of Education, Culture, Sports, Science, and Technology, Japan.

${ }^{1}$ T. Dalibor, G. Pensl, H. Matsunami, T. Kimoto, W. J. Choyke, A. Schöner, and N. Nordell, Phys. Status Solidi A 162, 199 (1997).

${ }^{2}$ C. Hemmingsson, N. T. Son, O. Kordina, J. P. Bergman, E. Janzén, J. L. Lindström, S. Savage, and N. Nordell, J. Appl. Phys. 81, 6155 (1997).

${ }^{3}$ L. Storasta, J. P. Bergman, E. Janzén, A. Henry, and J. Lu, J. Appl. Phys. 96, 4909 (2004).

${ }^{4}$ K. Danno and T. Kimoto, J. Appl. Phys. 100, 113728 (2006).

${ }^{5}$ S. G. Sridhara, L. L. Clemen, R. P. Devaty, W. J. Choyke, D. J. Larkin, H. S. Kong, T. Troffer, and G. Pensl, J. Appl. Phys. 83, 7909 (1998).

${ }^{6}$ K. Danno and T. Kimoto, J. Appl. Phys. 101, 103704 (2007).

${ }^{7}$ Yu. A. Vodakov and E. N. Mokhov, Silicon Carbide 1973 (University of South Carolina Press, Columbia, SC, 1974), p. 508.

${ }^{8}$ G. Alfieri, E. V. Monakhov, B. G. Svensson, and A. Hallén, J. Appl. Phys. 98, 113524 (2005)

${ }^{9}$ M. L. David, G. Alfieri, E. M. Monakhov, A. Hallén, C. Blanchard, B. G. Svensson, and J. F. Barbot, J. Appl. Phys. 95, 4728 (2004).

${ }^{10}$ G. Alfieri and T. Kimoto, J. Appl. Phys. 101, 103716 (2007).

${ }^{11}$ S. Mitra, M. V. Rao, N. Papanicolaou, K. A. Jones, M. Derenge, O. W. Holland, R. D. Vispute, and S. R. Wilson, J. Appl. Phys. 95, 69 (2004).

${ }^{12}$ J. Wong-Leung and B. G. Svensson, Appl. Phys. Lett. 92, 142105 (2008).

${ }^{13}$ M. Canino, A. Castaldini, A. Cavallini, F. Moscatelli, R. Nipoti, and A. Poggi, Mater. Sci. Forum 527, 811 (2006).

${ }^{14}$ Y. Negoro, T. Kimoto, and H. Matsunami, J. Appl. Phys. 98, 043709 (2005).

${ }^{15}$ T. Troffer, M. Schadt, T. Frank, H. Itoh, G. Pensl, J. Heindl, H. P. Strunk, and M. Maier, Phys. Status Solidi A 162, 277 (1997).

${ }^{16}$ D. Åberg, A. Hallén, and B. G. Svensson, Physica B 273, 672 (1999).

${ }^{17}$ M. Laube, F. Schmid, G. Pensl, G. Wagner, M. Linnarsson, and M. Maier, J. Appl. Phys. 92, 549 (2002).

${ }^{18}$ D. Peters, R. Schörner, K.-H. Hölzlein, and P. Friedrichs, Appl. Phys. Lett. 71, 2996 (1997).

${ }^{19}$ J. F. Ziegler, Nucl. Instrum. Methods Phys. Res. B 136, 141 (1998).

${ }^{20}$ Y. Negoro, K. Katsumoto, T. Kimoto, and H. Matsunami, J. Appl. Phys. 96, 224 (2004).

${ }^{21}$ S. Weiss and R. Kassing, Solid-State Electron. 31, 1733 (1988).

${ }^{22}$ L. Storasta, H. Tsuchida, T. Miyazawa, and T. Ohshima, J. Appl. Phys. 103, 013705 (2008).

${ }^{23}$ L. Storasta, F. H. C. Carlsson, S. G. Sridhara, J. P. Bergman, A. Henry, T. Egilsson, A. Hallén, and E. Janzén, Appl. Phys. Lett. 78, 46 (2001).

${ }^{24}$ L. Patrick and W. J. Choyke, Phys. Rev. B 5, 3253 (1972).

${ }^{25}$ S. Yaguchi, T. Kimoto, N. Ohyama, and H. Matsunami, Jpn. J. Appl. Phys., Part 1 34, 3036 (1995).

${ }^{26}$ M. S. Janson, A. Hallén, P. Godignon, A. Yu. Kuznetsov, M. K. Linnarsson, E. Morvan, and B. G. Svensson, Mater. Sci. Forum 338, 889 (2000). 